\title{
ON THE TECHNICAL DESCRIPTION OF VALUE MEASURING METHODOLOGY
}

\author{
Tolga MATARACIOGLU \\ TUBITAK BILGEM Cyber Security Institute, Turkey
}

\begin{abstract}
Value Measuring Methodology (VMM) is a proven toolkit of existing techniques used to define, capture and measure both quantitative and qualitative value associated with information technology (IT) investments. It is based on public and private sector business and economic analysis theories and best practices. The VMM was first articulated in a report by Booz. Allen Hamilton in 2002 for the US Social Security Administration, as part of an electronic services project. The purpose of Value Measuring Methodology is to define, capture and measure value associated with electronic services unaccounted for traditional return on investment (ROI) calculations, to fully account for costs and to identify and consider risk.
\end{abstract}

\section{KEYWORDS}

Value Measuring Methodology, VMM, Return on Investment, Cost Element Structure

\section{ABBREVIATIONS}

\begin{tabular}{|l|l|}
\hline VMM & Value Measuring Methodology \\
\hline ROI & Return on Investment \\
\hline CES & Cost Element Structure \\
\hline
\end{tabular}

\section{INTRODUCTION}

The Value Measuring Methodology is composed of four steps: Develop a Decision Framework; Define Alternatives; Analyze Alternatives; Document and Communicate. Each step is necessary to ensure both qualitative and quantitative information is captured. Additionally, each step must be completed sequentially to ensure complete documentation and objectivity. The figure representing those steps is given below (figure-1). The input of the methodology is the requirements. The output of the first step is decision framework. The output of the second step is alternatives with estimate documenting value, cost, and risk, economic factors and assumptions. Comparison of cost, value and risk is the output of the third step. Finally, documentation, insight and support for improving decision making and performance measurement through Lessons Learned are the outputs of VMM. 
International Journal of Managing Value and Supply Chains (IJMVSC) Vol. 6, No. 2, June 2015

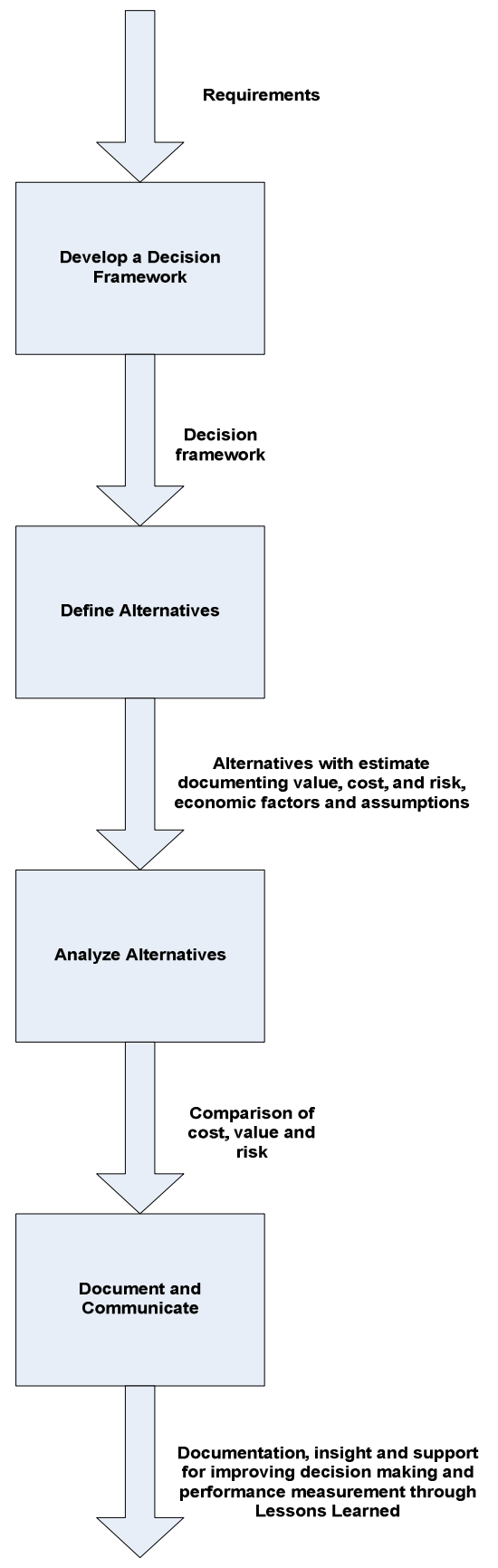

Figure1. Basic Steps of VMM

\section{BASIC STEPS OF VMM}

\section{Step 1: Develop A Decision Framework}

The output of this step is decision framework and this output is used by the second step. The cornerstone of VMM is the decision framework. Comprised of three structures: value, cost and 
International Journal of Managing Value and Supply Chains (IJMVSC) Vol. 6, No. 2, June 2015

risk. The framework provides decision makers with a blueprint for defining, analyzing and comparing alternatives.

This step is composed of four tasks:

- Task 1: Identify and define value structure

- Task 2: Identify and define risk structure

- Task 3: Identify and define cost structure

- Task 4: Begin documentation

These tasks are shown at figure-2.

The roles: Board/executive, Business Management

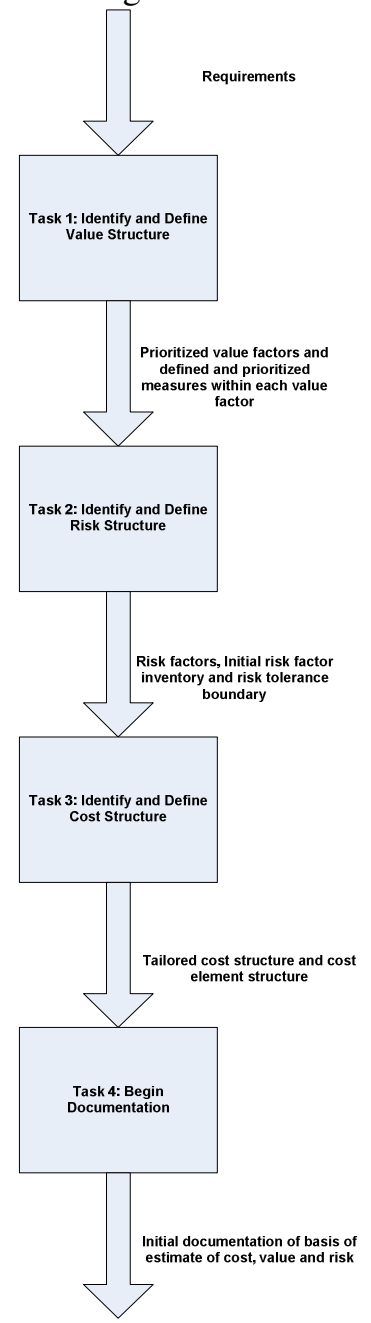

Figure 2 Tasks of Step 1

\section{Task 1: Identify and Define Value Structure}

The Value Structure is comprised of five Value Factors: direct user value, social value, government financial value, strategic political value and government operational foundational. 
The Value Structure describes and prioritizes benefits in two layers. The first layer is comprised of the Five Value Factors (Direct User Value, Social Value, Government Financial Value, Government Operational and Foundational Value, and Strategic/Political Value) that must be addressed when considering the ability of an initiative to deliver value to the government, direct users, and society at large. The second layer contains the measures that define those values in quantitative terms.

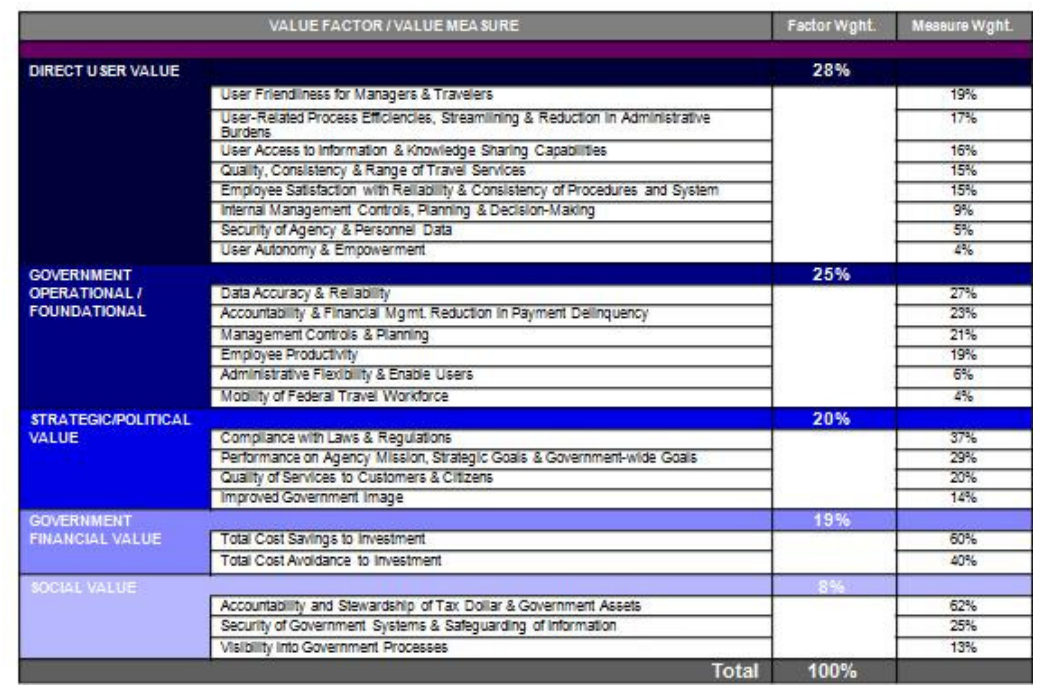

Figure 3 Value Structure

The outputs of this task are "Prioritized value factors" and "Defined and prioritized measures within each value factor". As seen in Figure 3, the first column is Value Factors, and the second is Value Measures.

The roles: Board/executive, Business Management

\section{Task 2: Identify and Define Risk Structure}

The outputs of this task are "Risk Factors, "Initial risk factor inventory" and "Risk tolerance boundary".

\begin{tabular}{|c|c|c|c|c|c|c|c|}
\hline & \multicolumn{5}{|c|}{ Value } & \multirow[b]{2}{*}{ Cost } \\
\hline & & $\begin{array}{c}\text { Direct } \\
\text { User }\end{array}$ & $\begin{array}{l}\text { Strategic I I } \\
\text { Political }\end{array}$ & $\begin{array}{c}\text { Gov. } \\
\text { Operational } \\
\text { / Foundational }\end{array}$ & Social & $\begin{array}{l}\text { Gov. } \\
\text { Financial }\end{array}$ & \\
\hline & Probability & Impact & Impact & Impact & Impact & Impact & \\
\hline $\begin{array}{c}\text { Risk } \\
\text { Factor } 1\end{array}$ & & & & & & & \\
\hline $\begin{array}{c}\text { Risk } \\
\text { Factor } 2\end{array}$ & & & & & & & \\
\hline $\begin{array}{c}\text { Risk } \\
\text { Factor } 3\end{array}$ & & & & & & & \\
\hline
\end{tabular}

Figure 4 Risk Structure

The roles: Board/executive, Business Management 


\section{Task 3: Identify and Define Cost Structure}

The outputs of this task are "Tailored cost structure" and cost element structure.

The Cost Element Structure (CES) captures the individual elements of cost associated with delivering value and mitigating risk.

The roles: Board/executive, Business Management

\section{Task 4: Begin Documentation}

The output of this task is "Initial documentation of basis of estimate of cost, value and risk".

Forcing the development of the decision framework, with the assignment of scores to intangibles allowing comparison to other intangibles as well as tangibles, eases the resolution of differences of perspectives between senior managers (e.g. Chief Financial Officer, Risk Manager, and the proposer of the initiative), allows changes to the scores to flow through to the rest of the process (especially the analysis of alternatives), and provides clarity of benefits to a board (before, during, and after the initiative), and clarity of priorities to people looking after more detailed aspects of the initiative. The same transparency of values apply if the proposal is developed at an enterprise level, or within a lesser organizational unit.

Major value factors (from which the value hierarchy is developed) include the following:

- Direct Customer Value: Benefits to customers/clients, e.g. convenient access, product enhancement.

- Social: Benefits to society as a whole, e.g. reducing CO2 emissions.

- Operational: Better operations and lowering barriers to future initiatives, e.g. improved infrastructure.

- Strategic: Contributions to strategic initiatives and fulfilling the mission of the organization

- Financial: Financial benefits, including increased revenue, decreased costs, and cost avoidance.

The roles: Board/executive, Business Management

\section{Step 2: Define Alternatives}

The output of this step is alternatives with estimate documenting value, cost, and risk, economic factors and assumptions

This step is composed of four tasks:

- Task 1: Identify and define value alternatives

- Task 2: Estimate value and cost

- Task 3: Conduct risk analysis

- Task 4: Ongoing documentation

The figure representing those tasks is given below.

The roles: Business Management, IT Management, Audit/Compliance 
International Journal of Managing Value and Supply Chains (IJMVSC) Vol. 6, No. 2, June 2015

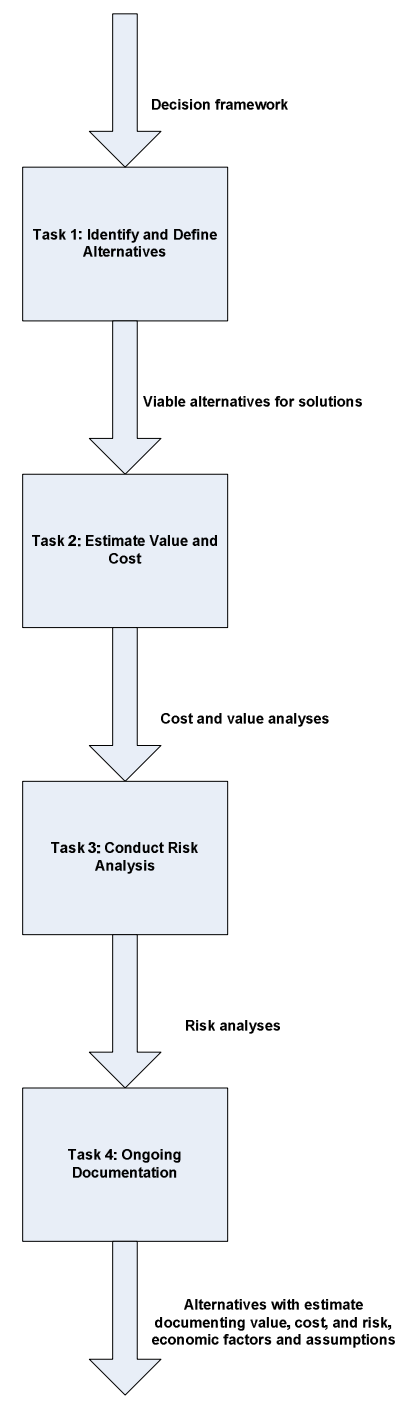

Figure 5 Tasks of Step 2

\section{Task 1: Identify and Define Alternatives}

The output of this task is "Viable alternatives for solutions".

The starting point for developing alternatives should be the information in the Value and Risk Structures and preliminary value drivers identified in the initial basis of estimate.

The roles: Business Management, IT Management, Audit/Compliance

\section{Task 2: Estimate Value and Cost}

The output of this task is "Cost and value analyses".

The techniques given below are used for cost estimation: 


\begin{tabular}{|l|l|}
\hline Parametric & $\begin{array}{l}\text { - Most often used when there are only a few key pieces of data that are known. } \\
\text { Based on historical data and mathematical expressions relating cost as the } \\
\text { dependent variable to selected, independent, cost-driving variables through } \\
\text { regression analysis. }\end{array}$ \\
$\begin{array}{l}\text { - The implicit assumption of this approach is that the same forces that affected } \\
\text { cost in the past will affect cost in the future. }\end{array}$ \\
$\begin{array}{l}\text { (a.k.a - "grass roots" or } \\
\text { "bottom-up"estimating) }\end{array}$ & $\begin{array}{l}\text { - Rolls up individual estimates for each element into the overall estimate. The } \\
\text { engineers performing the work usually provide these lower level estimates. } \\
\text { Involves the computation of the cost of a WBS element by estimating at the } \\
\text { resources to accomplish the work effort are readily distinguishable and } \\
\text { discernable. }\end{array}$ \\
\hline Analogous system & $\begin{array}{l}\text { - Performed on the basis of comparison and extrapolation to like items or efforts. } \\
\text { Cost data from one past program that is technically representative of the } \\
\text { program to be estimated serves as the basis of estimate. These cost data are } \\
\text { then subjectively adjusted upward or downward. }\end{array}$ \\
\hline $\begin{array}{l}\text { Vendor Quote / } \\
\text { Rough Order of } \\
\text { Magnitude (ROM) }\end{array}$ & $\begin{array}{l}\text { Might be used when the vendor is willing to provide informal cost information } \\
\text { and the cost analyst has concluded that a better cost approach does not exist. }\end{array}$ \\
\hline
\end{tabular}

Table 2 Cost Estimation Techniques

The roles: Business Management, IT Management, Audit/Compliance

\section{Task 3: Conduct Risk Analysis}

The output of this task is "Risk analyses". The figure for this task is given below:

\begin{tabular}{|c|c|c|c|c|}
\hline \multicolumn{5}{|c|}{ ALTERMATME 1 - COST RISK AMALYSIS } \\
\hline RISik & Probasing & Cost Impascis & impac & \\
\hline \multirow{3}{*}{ 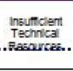 } & \multirow{3}{*}{$\rightarrow$} & 1.0 S) jthem Planning \& Development & Low & \\
\hline & & 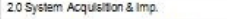 & High & \\
\hline & & 30 Sybtem Mamerance \& Operatons & Med & \\
\hline \multirow{3}{*}{ 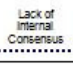 } & \multirow{3}{*}{.$^{H}$} & 1.0 Sy)tlem Planning \& Development & Med & \\
\hline & & 20 S) & Med & \\
\hline & & 30 s)btem Mamenance \& Operatons & Low & \\
\hline \multicolumn{5}{|c|}{ ALTERNATME 1 - VALUE RISK ANALYSIS } \\
\hline Flak & Probabing & Vaue impaciad & Impac & \\
\hline \multirow{2}{*}{ 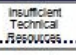 } & \multirow{2}{*}{ Med } & Tolat Cost Samings b inestment & Low & \\
\hline & & Tola Cost Avoddance to Imestment & Low & $4 \cdot \cdots$ \\
\hline \multirow{2}{*}{ 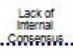 } & \multirow{2}{*}{$\ldots{ }^{\text {Mligh }}$} & Tolal Cost Savings to Imestment & Low & $4 \cdots$ \\
\hline & & Tola Cost Avodance is investmemt & Low & \\
\hline \multirow{7}{*}{$\begin{array}{c}\text { HWW SW } \\
\text { Falues } \\
\text { Reposament }\end{array}$} & \multirow{7}{*}{ Mes } & 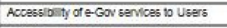 & High & \\
\hline & & Uger Trust in Internet Transactions & Hign & \\
\hline & & 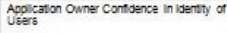 & Hign & \\
\hline & & Reduction of identry Fraud & High & \\
\hline & & Regusuatoy Complance & Hilgh & \\
\hline & & Total Cost in Saings investment & Hign & \\
\hline & & Tolal Cost Avodidance wo Imestment & Hign & \\
\hline
\end{tabular}

Figure 6 Risk Analysis

The roles: Business Management, IT Management, Audit/Compliance

\section{Task 4: Ongoing Documentation}

The output of this task is "Tailored basis of estimate documenting value, cost, and risk, economic factors and assumptions".

The roles: Business Management, IT Management, Audit/Compliance

\section{Step 3: Analyze Alternatives}

This step of VMM framework has five tasks:

- Task 1: Aggregate the cost estimate 
International Journal of Managing Value and Supply Chains (IJMVSC) Vol. 6, No. 2, June 2015

- Task 2: Calculate the return on investment

- Task 3: Calculate the value score

- Task 4: Calculate the risk score

- Task 5: Compare value, cost, and risk

The output of this step is comparison of cost, value and risk.

The figure representing those tasks is given below.

The roles: Business Management, IT Management, Audit/Compliance

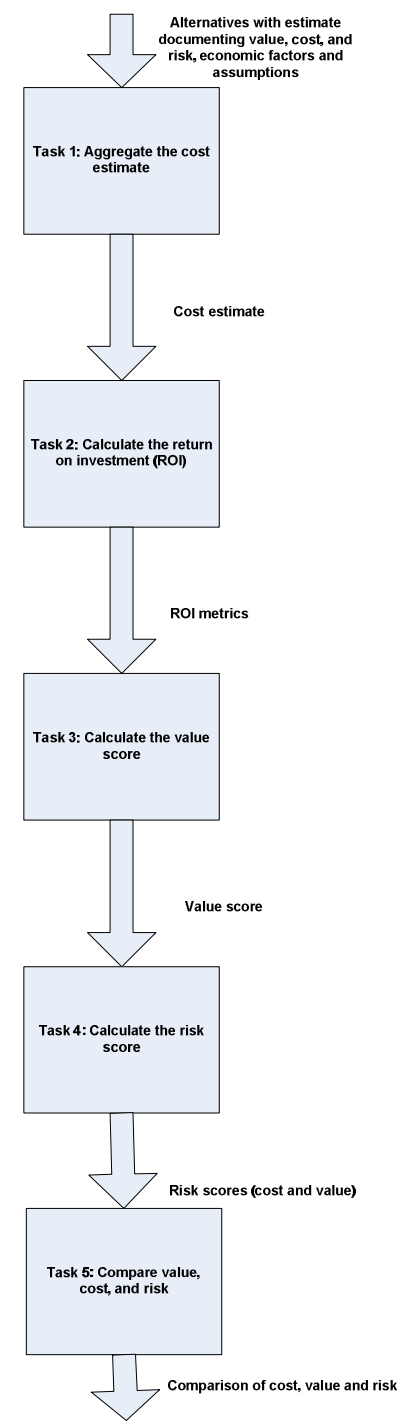

Figure 7 Tasks of Step 3

\section{Task 1: Aggregate the Cost Estimate}

The output of this task is "Cost estimate". 
International Journal of Managing Value and Supply Chains (IJMVSC) Vol. 6, No. 2, June 2015

The roles: Business Management, IT Management, Audit/Compliance

\section{Task 2: Calculate the Return on Investment}

The output of this task is "ROI metrics".

The roles: Business Management, IT Management, Audit/Compliance

Task 3: Calculate the Value Score

The output of this task is "Value score".

The roles: Business Management, IT Management, Audit/Compliance

\section{Task 4: Calculate the Risk Score}

The output of this task is "Risk scores (cost and value)".

The roles: Business Management, IT Management, Audit/Compliance

Task 5: Compare Value, Cost and Risk

The output of this task is "Comparison of cost, value and risk".

The roles: Business Management, IT Management, Audit/Compliance

\section{Step 4: Document and Communicate}

This step primarily focuses on effective communication. This step of VMM framework has four tasks:

- Task 1: Communicate value to customers and stakeholders

- Task 2: Prepare budget justification document

- Task 3: Satisfy ad-hoc reporting requirement

- Task 4: Use lessons learned to improve processes

The output of this step is documentation, insight and support for improving decision making and performance measurement through Lessons Learned

The figure representing those tasks is given below.

The roles: Board/Executive, Business Management, IT Management, Audit/Compliance 
International Journal of Managing Value and Supply Chains (IJMVSC) Vol. 6, No. 2, June 2015

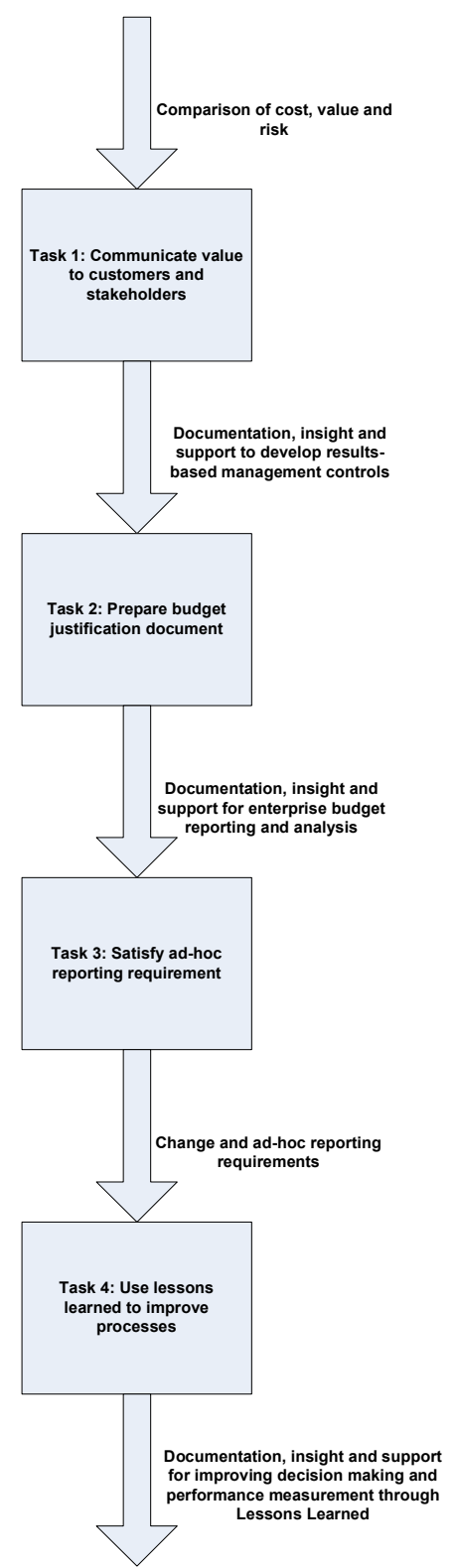

Figure 8 Tasks of Step 4

\section{Task 1: Communicate Value to Customers and Stakeholders}

The output of this task is "Documentation, insight and support to develop results-based management controls". This output becomes an input for customers and stakeholders.

The roles: Board/Executive, Business Management

\section{Task 2: Prepare Budget Justification Document}

The output of this task is "Documentation, insight and support for enterprise budget reporting and analysis".

The roles: Business Management, IT Management 


\section{Task 3: Satisfy Ad-Hoc Reporting Requirement}

The output of this task is "Change and ad-hoc reporting requirements". The events initiating this task are the modifications made on Project investment plan due to funding authorities, agency partners, market pricing fluctuations or portfolio managers.

The roles: Business Management, IT Management, Audit/Compliance

\section{Task 4: Use Lessons Learned to Improve Processes}

The output of this task is "Documentation, insight and support for improving decision making and performance measurement through Lessons Learned".

The roles: Board/Executive, Business Management, IT Management, Audit/Compliance

\section{DISCUSSION}

We could not obtain enough information from the available and official VMM documents in order to determine the "roles". So we mainly benefited from the Val IT framework document while determining the roles [8].

The purposes of VMM and Val IT are quite similar. VMM is more detailed than Val IT. It provides more specific guidance on the different types of value (both tangible and intangible). VMM also provides more specific guidance on how to compare the tangibles values with intangible value from individual projects to help maintain balance [9]. Once the VMM and Val IT are compared, we came to conclusion that the roles at Val IT document can be used at the VMM steps and tasks. There are mainly four distinct roles in Val IT documentation [8]. These are board/executive, business management, IT management and audit/compliance. We used these roles at our VMM project as well. Also by using [8], we matched these roles with the steps/tasks by using Val IT document. Although, Val IT and VMM have some similarities and same purposes, it is possible to make mistakes during this phase. This phase of project was least understood phase for us.

\section{CONCLUSION}

The conclusion part of the paper is composed of two subsections. In first subsection, we conveyed the results of the discussions. The second subsections include the details of our working style of this paper.

\section{REFERENCES}

[1] "Value Measuring Methodology Highlights", CIO Council, Best Practices Committee, 2002.

[2] K. Folley, "Using the Value Measuring Methodology to Evaluate Government Initiatives", Proceedings of the 2006 Crystal Ball User Conference.

[3] "VMM Frequently Asked Questions", Office of Electronic Government and Technology.

[4] “The Value of IT Investments: It's not just Return on Investment", Best Practices Committee, VMM.

[5] "Value Measuring Methodology How-to-Guide", CIO Council, Best Practices Committee, 2002.

[6] "Value Measuring Methodology", Council for Excellence in Government: Benefits Assessment Workshop, 2003.

[7] Booz, Hallen, Hamilton, “An Introduction to Value Measuring Methodology”, date not submitted. 
International Journal of Managing Value and Supply Chains (IJMVSC) Vol. 6, No. 2, June 2015

[8] IT Governance Implementation Guide Using COBIT and VAL IT 2nd Edition, IT Governance Institute, 2007

[9] Val IT Wiki Page, http://en.wikipedia.org/wiki/Val_IT

\section{AUTHOR}

\section{Tolga MATARACIOGLU}

After receiving his BSc degree in Electronics and Communications Engineering from Istanbul Technical University in 2002 with high honors, he received his MSc degree in Telecommunications Engineering from the same university in 2006. He is now pursuing his $\mathrm{PhD}$ degree in Information Systems from Middle East Technical University. He is working for TUBITAK BILGEM Cyber Security Institute as chief researcher. He is the author of many papers about information security published nationally and internationally. He also trains various organizations about information security. His areas of specialization are system design and security, operating systems security, and social engineering.

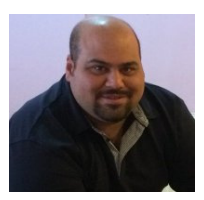

